\title{
Regulation of vascular morphogenesis by Notch signaling
}

\author{
Cristina Roca and Ralf H. Adams ${ }^{1}$ \\ Vascular Development Laboratory, Cancer Research UK London Research Institute, London WC2A 3PX, United Kingdom
}

The Notch pathway is a versatile regulator of cell fate specification, growth, differentiation, and patterning processes in metazoan organisms. In the vertebrate cardiovascular system, multiple Notch family receptors and several of their Jagged and Delta-like ligands are expressed during critical stages of embryonic and postnatal development. Functional studies in mice, fish, tumor models, and cell culture systems have shown that the angiogenic growth of the blood vessel network, the proliferation of endothelial cells, and the differentiation of arteries and veins are controlled by Notch signaling. Moreover, Notch pathway components play important roles in human pathological conditions involving the vasculature, namely CADASIL (cerebral autosomal dominant arteriopathy with subcortical infarcts and leukoencephalopathy) and Alagille syndrome. Recent findings highlight the Notch ligand Delta-like 4 as a key regulator of tumor angiogenesis and suggest that this protein might be a promising target for cancer therapy.

Blood vessels form an extensive hierarchical network of arteries, capillaries, and veins that provides a conduit system for the transport of liquids, solutes, gases, macromolecules, and cells within the vertebrate body (Carmeliet 2003; Jain 2003; Adams and Alitalo 2007). During fetal and postnatal growth, the size and transport capacity of the vasculature need to expand significantly. Although various mechanisms for the formation of new blood vessels are known, angiogenesis-that is, the expansion of a pre-existing vessel network through a combination of sprouting, proliferation, and remodeling processes-predominates in most settings. In the adult, blood vessels acquire a quiescent, nonangiogenic state but retain considerable growth potential that is activated during wound healing as well as in certain physiological processes. Unfortunately, angiogenesis is also part of the pathogenesis of several human diseases and plays a key role in tumor growth and metastasis. While it is desirable to block the growth of new blood vessels under these circumstances, the controlled stimulation of an-

[Keywords: Dll4; Notch; angiogenesis; endothelial cell; sprouting] ${ }^{1}$ Corresponding author.

E-MAIL ralf.adams@cancer.org.uk; FAX 44-207-269-3581.

Article is online at http://www.genesdev.org/cgi/doi/10.1101/gad.1589207. giogenesis might be beneficial in ischemic conditions when the local blood supply is impaired.

The Notch pathway is an evolutionary highly conserved signaling machinery with roles in invertebrates as well as in almost every vertebrate organ and tissue. Notch receptors are transmembrane proteins with large extracellular domains containing numerous epidermal growth factor (EGF)-like repeats (Fig. 1). In mammals, four Notch molecules (Notch1-Notch4) interact with five ligands, namely Delta-like 1, Delta-like 3, Delta-like 4, Jagged1, and Jagged2. Like their receptors, Notch ligands are also EGF repeat-containing transmembrane proteins, and they are orthologs of invertebrate Delta and Serrate/Lag-2 proteins, respectively (Fig. 1; Weinmaster 2000; Lai 2004; Le Borgne et al. 2005; Bray 2006; Hurlbut et al. 2007). Several Notch receptors and ligands as well as components of the downstream signaling machinery and various accessory proteins are indispensable for vascular morphogenesis. In this review, we summarize some of the principles controlling blood vessel growth, highlight the function of Notch signaling in the regulation of physiological and pathological angiogenesis, and compare these roles with other processes of tubulogenesis.

\section{The Notch signaling pathway}

Notch receptors are synthesized as single-chain precursors that, after essential glycosylation involving the enzyme Protein O-fucosyl transferase (POFUT1) in the endoplasmic reticulum, are cleaved into noncovalently linked extracellular (NECD) and intracellular (NICD) subunits by the protease furin in the trans-Golgi network (Fig. 1; Weinmaster 2000; Le Borgne et al. 2005; Bray 2006; Hurlbut et al. 2007). The NECD domain contains the large array of (depending on the particular Notch receptor) 29-36 EGF-like repeats, some of which are essential for ligand binding. Three cysteine-rich Notch/LIN-12 repeats help to prevent ligand-independent signaling (Weinmaster 2000; Le Borgne et al. 2005; Bray 2006; Hurlbut et al. 2007). The NICD includes six tandem ankyrin repeats, a glutamine-rich domain, and a C-terminal PEST sequence that facilitates rapid proteolytic degradation of the protein (Fig. 1). The ligands, collectively referred to as DSL (for Delta/Serrate/Lag-2), 


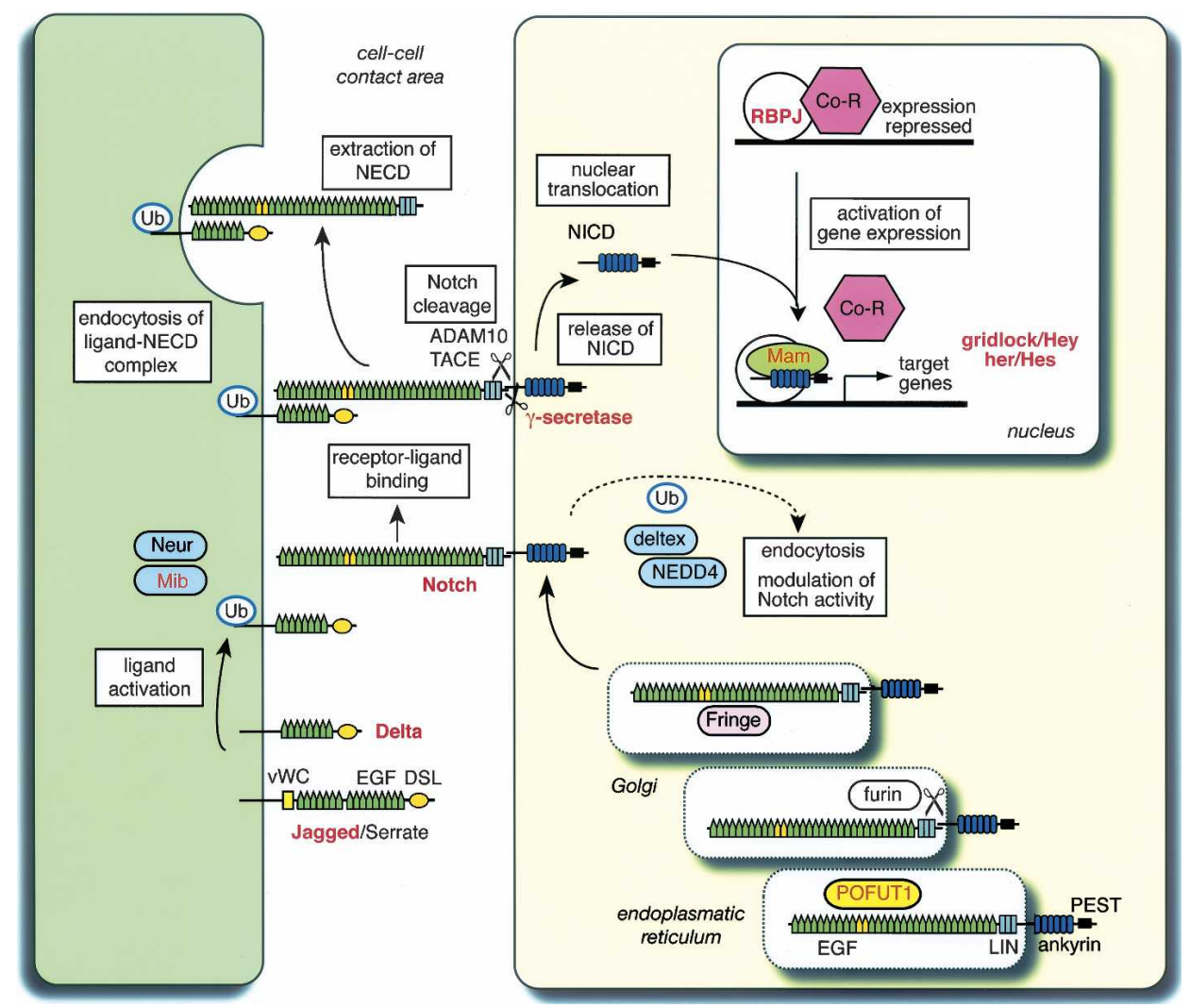

Figure 1. The Notch signaling pathway. Post-translational processing of the Notch preproprotein involves glycosylation and activity of POFUT1, as well as cleavage by the protease furin. Fringe-mediated glycosylation modulates Notch responses to ligands. Modification by the E3 ubiquitin ligases Mib and Neur enable DSL proteins to signal through Notch. Notch receptor activity is modulated by ubiquitination involving Nedd4 and deltex proteins. After ligand binding, Notch is processed by ADAM10/TACE and $\gamma$-secretase. The NECD is extracted from the plasma membrane by trans-endocytosis into the DSL-presenting cell. Nuclear translocation of the NICD and its interaction with RBP-J/CSL and the coactivator Mam trigger the expression of target genes such Hey and Hes. Domains shown in Notch are EGF-like repeats (green), some of which are involved in DSL binding (orange), Notch/LIN-12 repeats (gray), a single transmembrane (TM) region, intracellular ankyrin repeats (blue), and the C-terminal PEST sequence (black). Ligands contain an $\mathrm{N}$-terminal DSL domain (orange), EGF repeats (green), a transmembrane region, and a cytoplasmic area with a C-terminal PDZ-binding motif. In addition, Jagged/Serrate proteins contain an additional von Willebrand factor (vWF) type C-like domain. Gene products printed in red have known functions in angiogenesis.

contain an N-terminal, extracellular DSL motif mediating receptor binding followed by a variable number of EGF-like repeats (eight in mammalian Delta-like and 15-16 in Jagged ligands) (Bray 2006). Jagged/Serrate proteins have an extra cysteine-rich domain with homology with the von Willebrand factor in proximity to the transmembrane region (Fig. 1). Little is known about the DSL cytoplasmic domain except for a conserved C-terminal PDZ-binding motif. Binding and ubiquitination of DSL proteins by the E3 ubiquitin ligases Neuralized (Neur) and Mind bomb (Mib) are essential for ligand activation (Le Borgne and Schweisguth 2003; Le Borgne et al. 2005; Pitsouli and Delidakis 2005; Chitnis 2006). This ubiquitination and the activity of the endocytic ubiquitin-binding protein Epsin are requirements for DSL internalization from the cell surface and Notch signaling (Overstreet et al. 2004; Tian et al. 2004; Wang and Struhl 2004, 2005; Le Borgne et al. 2005; Chitnis 2006).

Upon ligand binding, Notch undergoes two further proteolytic cleavages. Extracellular proteases of the
ADAM/TACE/kuzbanian family sever the Notch extracellular domain. Due to this cleavage and/or conformational changes triggered by ligand-dependent trans-endocytosis of the NECD, Notch becomes susceptible to processing by $\gamma$-secretase, which releases the NICD (Fig. 1; Weinmaster 2000; Selkoe and Kopan 2003; Schweisguth 2004; Nichols et al. 2007a). Following translocation of the NICD into the nucleus, its interaction with the DNA-binding protein RBP-J [also named CSL after mammalian CBF1, Drosophila $\mathrm{Su}(\mathrm{H})$, and Caenorhabditis elegans LAG-1] and its coactivator Mastermind (Mam) leads to the displacement of corepressor proteins and associated chromatin-modifying factors from RBP-J/CSL. This process triggers the transcription of Notch target genes such as the basic helix-loop-helix (bHLH) proteins Hairy/Enhancer of Split (Hes) and Hes-related proteins (Hey), which, in turn, act as transcriptional regulators of further downstream genes (Lai 2002a; Fischer and Gessler 2003; Iso et al. 2003; Bray 2006; Ehebauer et al. 2006). Some evidence suggests that Notch can also signal 
in a RBP-J/CSL-independent mode (Martinez Arias et al. 2002).

The ankyrin repeats within the NICD are necessary for its signal transduction activity and are also targets for modification (Fig. 1; Struhl et al. 1993). Ubiquitination by the HECT domain family E3 ligases $\mathrm{Su}(\mathrm{dx})$ and NEDD4 promotes Notch degradation and thereby negatively regulates signaling (Lai 2002b; Sakata et al. 2004; Wilkin et al. 2004; Le Borgne et al. 2005; Nichols et al. 2007b). In contrast, ubiquitination within the NICD ankyrin repeats by the Ring finger E3 ligase Deltex can antagonize $\mathrm{Su}(\mathrm{dx})$ and, depending on cell type and context, promote or decrease Notch activity (Lai 2002b; Le Borgne et al. 2005; Wilkin and Baron 2005; Bray 2006; Nichols et al. 2007b).

Notch receptors are also modulated by glycosylation within several of the extracellular EGF repeats by the glycosyltransferase Fringe in the Golgi (Fig. 1). These modifications inhibit the ability of Notch to be activated by Jagged/Serrate ligands, whereas they potentiate activation by Delta-like proteins (Haines and Irvine 2003; Bray 2006).

Tissue-specific expression of Notch and Delta-like/ Jagged molecules, the modulation of their signaling by post-translational modification, and differences in the regulation of downstream target genes can help to explain the many different functional roles of the pathway. For example, initially subtle differences in Notch expression and signaling can single out individual cells from a group of equivalent neighbors and thereby impose differential behavior and differentiation fates (Lai 2004; Schweisguth 2004). Asymmetrical inheritance of Notch regulators, such as of the cytoplasmic adapter protein and Notch inhibitor Numb, is capable of directing the progeny of cell divisions into distinct lineages. Notch signaling can also separate subpopulations of cells and thereby help to generate tissue boundaries (Irvine 1999; Lai 2004; Schweisguth 2004). Dynamic and sometimes even oscillating expression of Notch pathway molecules leads to complex spatiotemporal patterns of Notch function during tissue morphogenesis (Holley and Takeda 2002; Pourquie 2003; Claxton and Fruttiger 2004; Giudicelli and Lewis 2004). Such elaborate, dynamic, and partially overlapping expression of multiple receptors (Notch1, Notch3, and Notch4) and ligands (Dll1, Dll4, Jagged1, and Jagged2) in vascular cells suggests important roles for Notch in the growth and differentiation of blood vessels.

\section{Angiogenic sprouting and tubulogenesis}

Most data addressing angiogenesis at the cellular level in vivo come from a few and relatively specialized model systems such as the developing mouse retina, the growth of intersegmental vessels in the zebrafish embryo, or tumor xenograft models. For example, the cup-like retina of the mouse starts out as an avascular tissue in the embryo, and only after birth do blood vessels rapidly grow in from the center (the bottom of the cup) toward the periphery (the upper rim) (Dorrell et al. 2002; Gari- ano 2003; Fruttiger 2007). This unusual—compared with most other tissues-growth pattern facilitates the analysis of the initially planar, two-dimensional vasculature in the retina at great detail. Previous work has shown that this rapid and highly directional growth of blood vessels is controlled by a spatial concentration gradient of matrix-anchored vascular endothelial growth factor A (VEGF-A) released by astrocytes in response to local hypoxia (Fig. 2; Stone et al. 1995; Dorrell et al. 2002; Gerhardt et al. 2003). VEGF-A is a very potent chemoattractive signal for endothelial cells (ECs) and promotes the polarized sprouting of specialized ECs, so-called tip cells, at the leading edge of the vascular plexus (Fig. 2). Tip cells lack a lumen, are not perfused by blood, and extend numerous long filopodia to explore growth factor signals and guidance cues in the surrounding tissue (Fig. 2; Dorrell et al. 2002; Ruhrberg et al. 2002; Gerhardt et al. 2003).

Whereas the explorative, invasive nature of tip cells leads to an extension of the endothelial network along the VEGF-A gradient, a second process, tubulogenesis, is required for the generation of patent, blood-carrying vessels. Although angiogenic growth in the retina, like in most other tissues, has so far not been observed dynamically, tip cells can be frequently seen in close contact with other tips (Fig. 5, below; Dorrell et al. 2002; Gerhardt et al. 2003), suggesting that the interaction of filopodial processes and, subsequently, cell bodies leads to bridge-like structures in which ECs lack long filopodia and no longer display tip cell features. It may be at this stage that sprouts are converted into new tubules, form anastomoses, and become part of a simple, plexus-like network at the vascular perimeter (Fig. 2). ECs in this plexus are sometimes referred to as "stalk cells" in the literature because, in contrast to tip cells, they lack long filopodia, enclose a luminal space, and thereby form a patent tubule at the stalk of vascular sprouts (Gerhardt et al. 2003). Stalk ECs in the retina also show a high level of proliferation, which supports the growth of the network (Gerhardt et al. 2003; Dorrell and Friedlander 2006). The emergence of new endothelial tip cells from the stalk plexus will promote further extension of the vascular network so that growth of the vasculature is presumably achieved through repeated cycles of EC sprouting and tubulogenesis. In this model of angiogenic growth, sprouting and tubulogenesis are equally essential, but play rather opposite roles and need to be carefully balanced.

\section{Angiogenic remodeling of blood vessels}

The morphology of the primitive plexus at the edge of the retinal vasculature is highly similar to some of the first blood vessels in the early vertebrate embryo, the so-called primary capillary plexi. These simple honeycomb-like tubular endothelial networks are formed de novo by a process termed vasculogenesis and permit presumably inefficient, albeit essential, blood circulation in the embryo. Extensive angiogenic remodeling converts the primary capillary plexi into arteries, veins, and cap- 

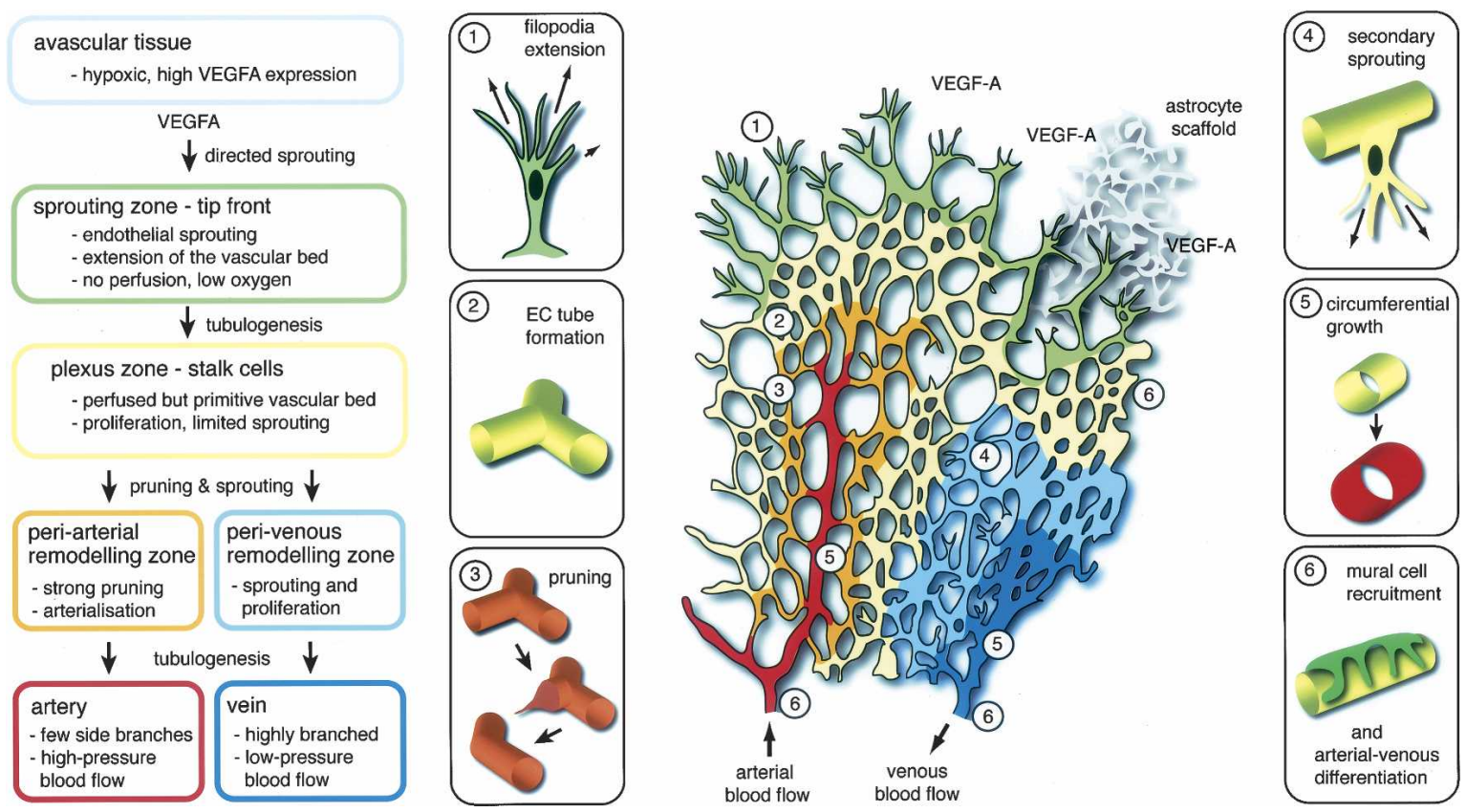

Figure 2. Growth of retinal blood vessels. (1) In the sprouting zone, directional extension of tip cells and filopodia promotes vascular growth along a gradient of matrix-bound VEGF-A, which is released by astrocytes in response to hypoxia. (2) Interaction of sprout tips and anastomosis generates a plexus zone of patent but nonhierarchically organized vessels behind the tip cell front. (3) Pruning of vessels is prominent in the periarterial remodeling zone. (4) Secondary sprouting in a perpendicular direction leads to the vascularization of deeper layers of the retina. (5) Differentiation of arteries and veins involves circumferential growth of blood vessels. (6) Recruitment of mural cells (i.e., pericytes and vSMCs) stabilizes the vasculature.

illary beds (Flamme et al. 1997). The plexus zone in the retinal vasculature has a similar fate. While growth into the periphery continues, the region of the plexus that is closer to the center of the retina is remodeled by pruning and secondary sprouting processes (Fig. 2). Pruning is most pronounced in areas in close proximity to arteries so that the periarterial vasculature is relatively sparse and contains only few branchpoints. In contrast, the perivenous vasculature remodels at a much slower rate, is a site of extensive EC proliferation, retains a higher density of vessels and branchpoints, and contains numerous secondary sprouts emerging from capillaries (Fig. 2). Although it is unclear whether these regional features are caused by hemodynamic factors (i.e., differences in the pressure and speed between arterial and venous blood flow), the concentration of oxygen in the blood stream, differential gene expression in arteries and veins, or a combination of all three, angiogenic remodeling around the arterial branch appears to strongly favor tube formation over new sprouting whereas the perivenous vasculature is permissive for both processes (Fig. 2).

A key step of endothelial tubulogenesis is the conversion of small capillary-like microvessels that contain only one or two ECs in each cross-section into larger tubes in which many ECs make tightly sealed lateral contacts with their neighbors. This circumferential growth occurs both within the arterial and venous branch of the vasculature and crucially increases blood flow toward and from capillary beds, respectively. Defects in angiogenic sprouting frequently lead to a strong increase in vessel diameter, presumably because additional ECs are incorporated into the wall of existing tubes and are no longer directed into new sprouts and branches (Ruhrberg et al. 2002; Nakatsu et al. 2003; Erber et al. 2006). Such phenotypes suggest that the balance between endothelial proliferation and new sprouting might also be a determinant of the normal circumferential growth seen in larger blood vessels and, particularly, in arteries and veins.

\section{Regulation of arteriovenous (AV) identity by Notch}

Like the primary capillary plexi, the dorsal aorta and the cardinal vein are directly formed in the early embryo through the assembly of endothelial progenitor cells (angioblasts); i.e., vasculogenesis (Fig. 3; Risau and Flamme 1995). Suggesting a role of genetic pathways in AV differentiation, arteries and veins not only differ in their function and morphology but also, even before the onset of blood circulation, in their gene expression profiles. Such artery-specific expression has been reported for several Notch receptors and ligands such as Dll4 in mouse and zebrafish (Shutter et al. 2000; Mailhos et al. 2001; Leslie et al. 2007; Siekmann and Lawson 2007). Lawson et al. (2001) have shown that disruption of Notch signaling due to mutations in the zebrafish mindbomb gene leads to loss of artery-specific markers such as ephrin-B2, a small transmembrane protein and ligand for Eph family receptor tyrosine kinases. In contrast, EphB4, a receptor for ephrin-B2 and normally most prominently expressed 


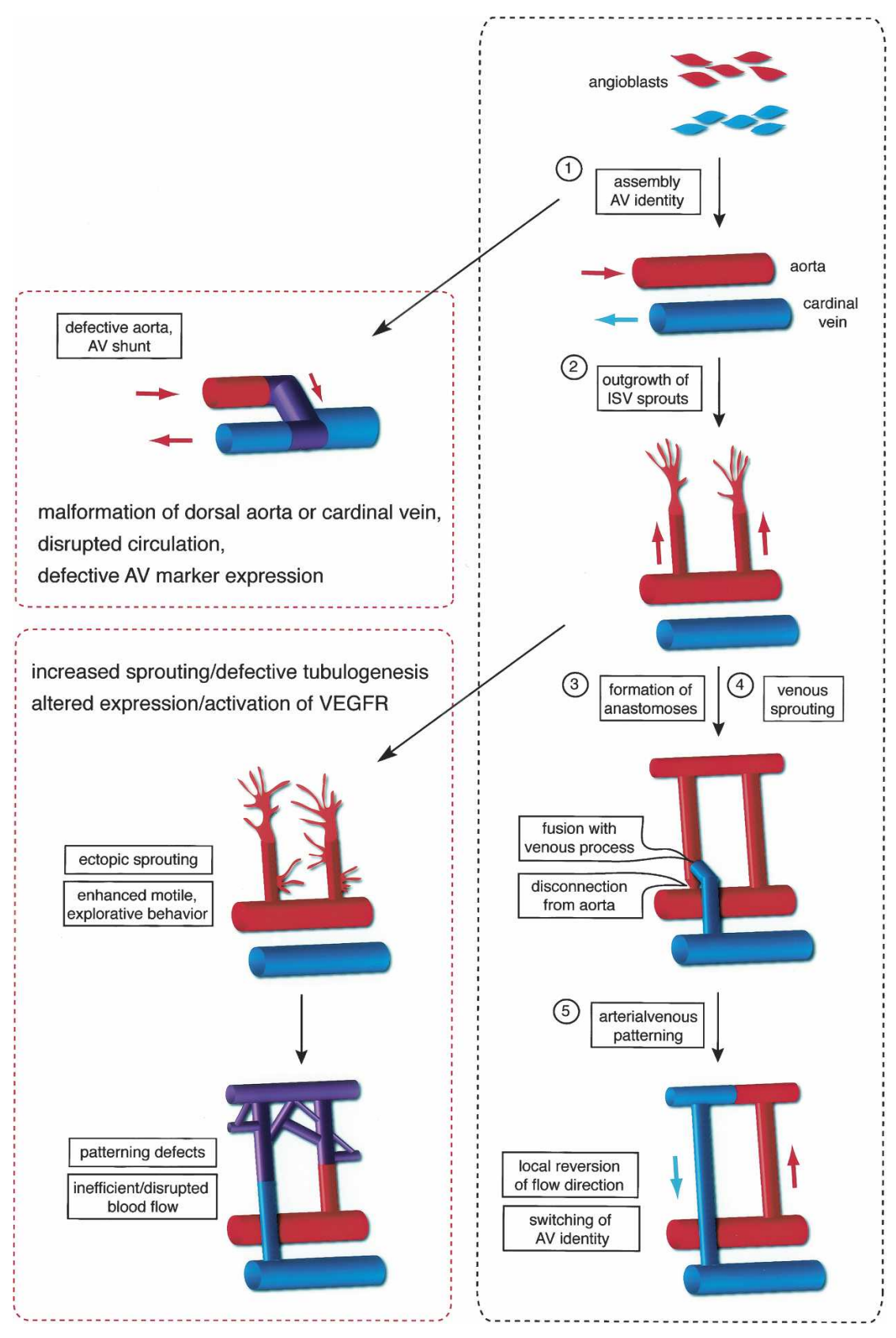

Figure 3. Notch function in the formation of dorsal aorta, cardinal vein, and intersegmental vessels. (1) Schematic representation of angioblasts assembly into aorta and cardinal vein. (Top left box) These vessels are defective in Notch pathway mutants in fish (mindbomb, gridlock) and mice (Rbpsuh, Hey1/Hey2, Pofut1, Dll4, Mib1, Jagged1, Notch1, Notch1/ Notch4). In zebrafish, genetic manipulation of Notch causes AV shunts. (2) Outgrowth of intersegmental vessels (ISV) from the aorta into dorsal direction in the zebrafish embryo. (3) Anastomosis gives rise to an arterial network. (4) Sprouting from the cardinal vein and reconnection of intersegmental vessels generates a pattern of alternating arteries and veins. (5) Reversion of blood flow through venous intersegmental vessels and adjustment of AV identity. (Bottom left box) Defective Notch signaling (rbpsuh, dll4, inhibition of $\gamma$-secretase) increases the explorative activity of intersegmental vessel ECs and compromises the patterning of blood vessels in zebrafish. Increased tip cell formation also disrupts blood vessel morphogenesis in response to reduced Dll4 expression or blocking of Notch activity in mice and tumor blood vessels. on veins, is misexpressed in mindbomb mutant arteries. Conversely, ectopic activation of the Notch pathway represses expression of EphB4 and the VEGF receptor flt4 (VEGFR-3), another venous marker in zebrafish, and thereby imposes a more artery-like molecular profile on veins (Lawson et al. 2001). Changes in the AV gene expression profile in mindbomb mutants are accompanied by vascular malformations. For example, AV shunts between the dorsal aorta and the posterior cardinal vein prevent normal blood circulation in the trunk (Fig. 3; Lawson et al. 2001).

Very similar AV shunts are caused by mutations in the zebrafish gridlock gene, which encodes a transcriptional regulator acting downstream from Notch and is homolo- gous to mammalian HEY2 (Zhong et al. 2000, 2001). Gridlock is expressed in the arterial endothelium but also in the lateral plate mesoderm and therefore presumably in the angioblasts that will form the dorsal aorta and cardinal vein (Zhong et al. 2001). The AV fate of these EC precursors appears to be predetermined in a Notch-dependent fashion. Knockdown of gridlock suppresses the expression of arterial markers (such as ephrin-B2) and leads to an expansion of the contiguous regions of the vein. In contrast, gridlock overexpression suppresses veins without increasing arteries, suggesting that the role of gridlock is the repression of venous differentiation rather than the induction of arterial differentiation (Zhong et al. 2001). 
Zebrafish genetics also allowed some insight into the genetic regulation upstream of Notch. The morphogen Sonic Hedgehog (Shh) is responsible for the induction of VEGF-A in the somitic tissue close to the aorta. In turn, this expression of VEGA-A up-regulates Notch pathway components in the aorta and thereby controls AV differentiation (Lawson et al. 2002).

Genetic experiments in mice have shown that the orphan nuclear receptor COUP-TFII (encoded by the gene Nr2f2) promotes venous EC differentiation by suppressing Notch signaling (You et al. 2005). Consequently, veins acquire arterial features in Nr2f2 knockout mice, whereas arterial markers are suppressed by EC-specific overexpression of the orphan receptor (You et al. 2005).

Studies with various Notch reporters have shown that arteries are also major sites of Notch signaling in mice (Duncan et al. 2005; Vooijs et al. 2007), and arterial specification is defective in various Notch pathway mutants. For example, inactivation of the murine Rbpsuh gene (which encodes RBP-J) or the two transcription factor genes Hey1 and Hey2 leads to defects in vascular remodeling, hemorrhaging, disruption of the dorsal aorta, and strong reduction of arterial markers (Fischer et al. 2004; Krebs et al. 2004). Similar results have been reported in knockout mice lacking Mindbomb1 (which is essential for DSL activation), protein O-fucosyltransferase 1, Jagged1, Notch1, or both Notch1 and Notch4 (Xue et al. 1999; Krebs et al. 2000; Shi and Stanley 2003; Koo et al. 2005). The Dll4 gene, which is expressed in arterial ECs, is haploinsufficient, so that even heterozygosity causes malformation of arteries, including stenosis and atresia of the aorta, defective arterial branching, and loss of arterial markers such as ephrin-B2 (Gale et al. 2004; Krebs et al. 2004).

\section{Notch controls arteriogenesis in the adult}

In some settings-for example, in response to local obstruction of arteries-blood flow into the periphery is restored by the expansion of small (arteriolar) side branches to collateral arteries in a process termed arteriogenesis (Fig. 4; Heil et al. 2006). This enlargement of pre-existing vessels is initiated by physical forces such as increased shear stress, but it also involves inflammatory cells, cell proliferation, and the remodeling of the extracellular matrix (Fig. 4; Heil et al. 2006). Arteriogenesis is probably not only relevant for tissue repair processes but may be also part of the vascular expansion program triggered by tissue growth or physical exercise.

A recent study has identified the Notch ligand Dll1 as a critical regulator of postnatal arteriogenesis (Limbourg et al. 2007). In the vasculature, Dll1 is largely confined to the arterial endothelium, and expression is strongly upregulated during ischemia-induced arteriogenesis (Beckers et al. 1999; Limbourg et al. 2007). Postnatal functional studies in null mutants are precluded by the embryonic lethality of Dll1 knockout mice (Hrabe de Angelis et al. 1997). However, Dll1 ${ }^{+/-}$heterozygotes, which survive to adulthood, show reduced formation of collateral arteries and fail to restore blood flow into the
Figure 4. Arteriogenic blood vessel remodeling. (1) In response to local obstructions, arterial blood flow can be redirected gradually through small (arteriolar) side branches, which are remodeled into larger collaterals with increased blood transport capacity. (2) This remodeling process involves reorganization of the extracellular matrix (ECM) and cell proliferation processes. Multiple sheets of vSMC with intercalated layers of extracellular matrix and elastic fibers are characteristic for larger arteries. (3) Dll1 controls various aspects of arteriogenesis, presumably through interactions with Notch1. The receptor Notch3 controls the differentiation of arterial vSMCs.
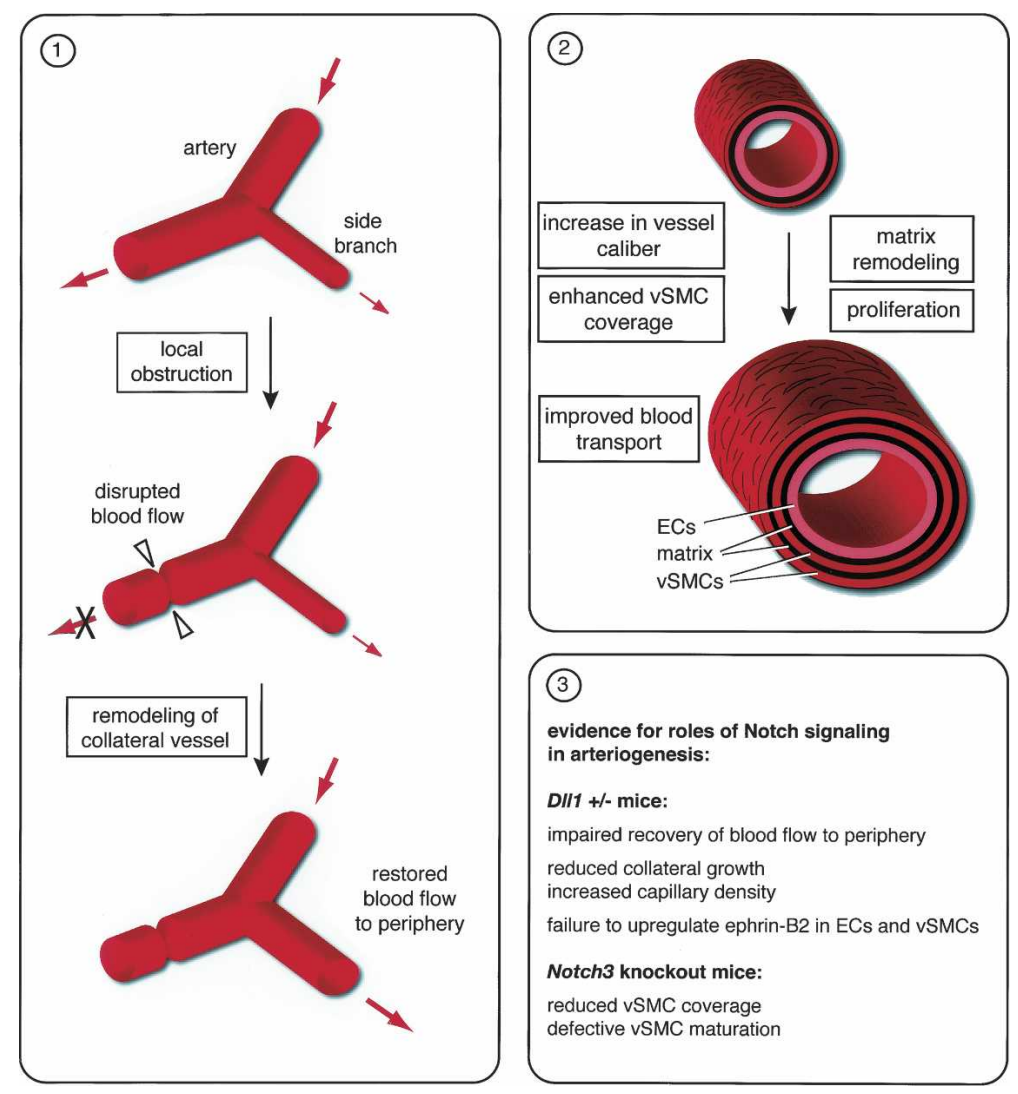
periphery in a hindlimb ischemia model (Limbourg et al. 2007). Loss of a single Dll1 allele is also sufficient to prevent ischemia-induced activation of Notch signaling and up-regulation of ephrin-B2 expression in arteries. In cultured cells, Dll1 expression is increased in response to VEGF-A and fibroblast growth factor-2 (FGF-2) and controls EC tube formation through ephrin-B2 (Limbourg et al. 2007). Recovery of blood flow in the hindlimb ischemia model is also compromised in Notch1 heterozygous knockout mice but not in Notch4-null mutants (Takeshita et al. 2007).

Vascular smooth muscle cells (vSMCs), contractile and matrix-producing support cells that are associated with arteries and, less prominently, with veins, also play critical roles in vascular maturation and arteriogenesis (Heil et al. 2006). In adult Notch3 knockout mice, some arteries are dilated, covered by a thinner than normal smooth muscle cell coat, and vSMCs fail to properly integrate into the vessel wall (Domenga et al. 2004). The main role of Notch3 in this process is apparently the regulation of vSMC differentiation. Notch3 mutant vSMCs fail to acquire mature markers such as the contractile protein smoothelin, whereas their proliferation and survival appear unaffected (Domenga et al. 2004).

\section{Selection of sprouting ECs}

A flurry of publications has recently established that the Notch pathway is involved not only in AV differentiation and arteriogenic growth processes but also in the regulation of angiogenic sprouting. During postnatal development of the mouse retina, Dll4 is expressed in the arterial endothelium but also in capillary beds. Different lines of evidence show that Dl14 promoter activity, transcripts, and protein are preferentially found at the angiogenic front of the growing vascular plexus; that is, the area in which the endothelium is engaged in active sprouting and remodeling. However, expression is very heterogeneous-some ECs are positive whereas others are not-and there is no clear-cut association with only tip or stalk cells (Claxton and Fruttiger 2004; Hellström et al. 2007; Hofmann and Iruela-Arispe 2007; Lobov et al. 2007). Spatial analysis of Notch activation by NICD antibodies or in TNR1 transgenic Notch reporter mice reveals a similar mosaic pattern of positive stalk and tip ECs at the vascular front (Hellström et al. 2007). These expression data indicate that ECs within the angiogenic vasculature of the retina are heterogeneous with respect to Notch signaling but offer few clues as to how this might be linked to specific functions within the angiogenic program.

More insight into the role of Dll4-Notch signaling was provided by genetic studies in mouse and fish. Although the functional characterization of Dll4 in postnatal mice is complicated by the embryonic lethality and haploinsufficiency of the knockout (Duarte et al. 2004; Gale et al. 2004; Krebs et al. 2004), the number of tip cells and branchpoints, endothelial proliferation, and the density of the retinal vasculature are all significantly increased in the fraction of surviving heterozygotes (Hellström et al. 2007; Lobov et al. 2007; Suchting et al. 2007). Molecular markers that are strongly, albeit not exclusively, expressed by tip cells, such as transcripts for the growth factor $P d g f b$ or the netrin receptor Unc5b, are up-regulated in the Dll4 mutant retinal endothelium (Hellström et al. 2007; Suchting et al. 2007). A similar phenotype of enhanced tip cell formation and endothelial sprouting results from the administration of recombinant, soluble Dll4/Fc protein, which acts as an antagonist of endogenous Dll4-Notch interactions, anti-Dll4 antibodies, or pharmacological blockage of Notch cleavage with the $\gamma$-secretase inhibitor DAPT (Ridgway et al. 2006; Hellström et al. 2007; Lobov et al. 2007; Suchting et al. 2007).

Studies in zebrafish have provided further insight into the role of Notch. In zebrafish embryos, intersegmental vessels sprout from the dorsal aorta and grow through the gaps between the somites into the dorsal trunk. Subsequently, a series of vessel fusion and pruning processes will give rise to a network of alternating arteries and veins that mediate the dorsoventral transport of blood (Fig. 3; Isogai et al. 2003). Blocking Dll4 expression or Rbpsuh-mediated Notch signaling during this process leads to enhanced sprouting, an increase in the number of tip cells, and aberrant branching, similar to what has been observed in the mouse retina (Leslie et al. 2007; Siekmann and Lawson 2007). Finally, time-lapse videomicroscopy of growing intersegmental vessels has directly demonstrated in vivo that the knockdown of Rbpsuh or Dll4 expression enhances the explorative behavior of endothelial sprouts (Leslie et al. 2007; Siekmann and Lawson 2007).

To address the question of whether the suppression of the tip cell phenotype requires cell-autonomous Notch activity, Siekmann and Lawson (2007) analyzed the distribution of Rbpsuh-deficient cells in mosaic fish embryos. Consistent with a model in which Notch promotes a quiescent, nonsprouting phenotype, ECs lacking Rbpsuh are preferentially found at the terminal tip of growing sprouts (Siekmann and Lawson 2007). Hellström et al. (2007) performed a similar analysis in ECspecific, inducible Notch1 mutant mice. In this chimeric setting resulting from the incomplete and patchy inactivation of the gene, Notch1-deficient cells are also preferentially found in tip cells within the retinal endothelium. In addition, studies utilizing three-dimensional in vitro EC culture systems, which permit the analysis of EC function in a simpler (albeit nonphysiological) context, had shown previously that ectopic Notch activation blocks VEGF-A-induced endothelial sprouting in a cell-autonomous fashion (Leong et al. 2002; Taylor et al. 2002; MacKenzie et al. 2004; Sainson et al. 2005). All these data from zebrafish embryos and the mouse retina together indicate that the activation of Notch signaling imposes a quiescent, nonsprouting phenotype on some ECs whereas adjacent, presumably transiently Dll4-expressing ECs are selected as tips (Fig. 5). This role offers an attractive explanation for the highly mosaic patterns of Dll4 expression and Notch activation in the retinal endothelium (Claxton and Fruttiger 2004; Hellström et al. 2007; Hofmann and Iruela-Arispe 2007; Lobov et al. 

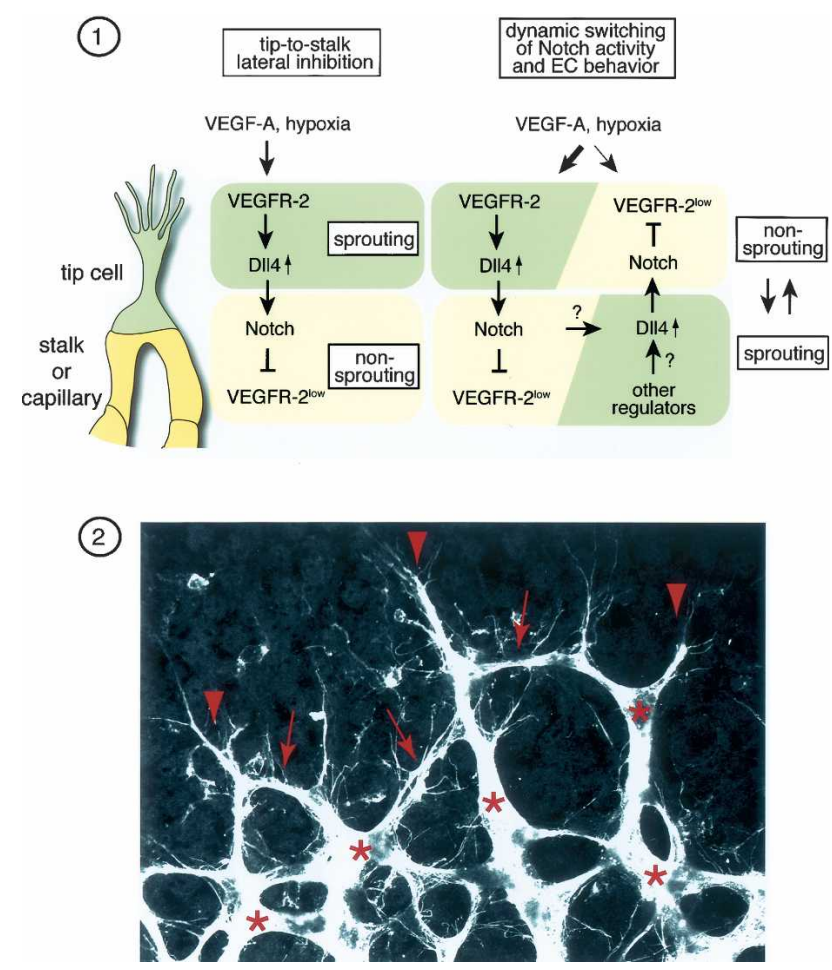

Figure 5. Dll4-Notch signaling and tip cell selection. (1) (Left) Selection of ECs for sprouting through the induction of Dll4 expression in response to VEGF-A, which leads to Notch activation in adjacent ECs and the suppression of VEGF receptor (VEGFR-2 in mouse, VEGFR-3 in zebrafish) expression. (Right) Model of transient tip cell selection by dynamic Dll4 expression and Notch activation. Brief expression of Dll4 in angiogenic ECs permits the rapid modulation between sprouting and nonsprouting phenotypes. (2) Image of isolectin-stained blood vessels in the postnatal retina. Endothelial phenotypes include tip cells with long filopodia (arrowheads), fusing tip cells undergoing anastomosis (arrows), and patent vessels in the stalk and capillary plexus region (asterisks).

2007) and indicates that Dll4 and Notch might help to maintain the integrity of angiogenic blood vessels by confining the capacity to induce and lead new vascular sprouts to a small fraction of cells.

\section{Cross-talk between VEGF and Notch signaling}

The ability of Notch to regulate endothelial sprouting is at least partially coupled to the VEGF pathway. Expression of Dll4 is induced in response to VEGF signaling and hypoxia (Liu et al. 2003; Patel et al. 2005; Hainaud et al. 2006; Diez et al. 2007; Lobov et al. 2007), which might also explain why the ligand is concentrated at the periphery of the growing retinal vasculature. The link between VEGF signaling and Dll4 appears to be reciprocal because expression of the VEGF receptor Vegfr2, which is normally concentrated within the sprouting and plexus zone, is up-regulated and transcripts are distributed more widely within the retinal endothelium of D114 heterozygotes (Suchting et al. 2007). At the same time, the level of $V e g f r 1$, a receptor that acts as an antagonistic inhibitor of VEGF signaling during development due to its relatively weak signaling activity, is reduced (Suchting et al. 2007). Dll4-Notch signaling also down-regulates VEGFR-2 expression in cultured human ECs (Williams et al. 2006). As further evidence for a direct functional link between Dll4 activity and VEGFR-2, the administration of VEGF-A antagonists such as soluble VEGFR1 (sFlt1) protein, a soluble chimeric receptor called VEGF trap, or antibodies blocking VEGFR2 inhibit tip cell formation and filopodia extension in the retina of Dll4 heterozygotes (Lobov et al. 2007; Suchting et al. 2007).

Despite these striking findings, a model in which Dll4-Notch signaling controls tip cells selection solely through VEGFR-2 expression is too simplistic (Fig. 5). Live video microscopy in zebrafish has shown that tip cells can quickly revert from their invasive phenotype and integrate into a blood vessel (Torres-Vazquez et al. 2004; Leslie et al. 2007). Dll4 is also regulated not only by VEGF-A but also through other pathways including Notch signaling (Shawber et al. 2003; Carlson et al. 2005), which might translate into a very transient pattern of Dll4 expression and activity (Fig. 5). Furthermore, the many connections between Notch and other pathways, such as signaling by TGF $\beta$, Hedgehog, or Wnt (Bray 2006; Hurlbut et al. 2007), may contribute to proliferation/apoptosis, cell migration, and branching morphogenesis in the vasculature. Notch has been also linked to the regulation of the cell cycle and, in particular, p21 $1^{\mathrm{WAF} 1 / \mathrm{CIP} 1}$, a regulator of cyclins and cyclin-dependent kinases (Noseda et al. 2004; Devgan et al. 2005; Sarmento et al. 2005), which may in part explain the elevated EC proliferation seen in DI14 heterozygous retinae.

Tip cell selection within the angiogenic front is unlikely to be the only function of Dll4 in the vasculature. Expression of Dll4 is high in the arterial endothelium of the retina and other tissues (Claxton and Fruttiger 2004; Hellström et al. 2007; Hofmann and Iruela-Arispe 2007; Lobov et al. 2007). Moreover, defective AV marker expression and aorta defects in D114 knockout mice (Gale et al. 2004; Krebs et al. 2004) suggest that the ligand is involved in the morphogenesis of these vessels. It is appealing to speculate that high levels of Notch activation in arteries, triggered by Dll4 and perhaps Dll1 and Jagged1, might be at least in part responsible for the low levels of sprouting and endothelial proliferation in these vessels. In response to overexpression of Dll4 in experimental tumors, intratumor blood vessels are straight with relatively few side branches, appear well perfused, and contain a reduced number of proliferating ECs, and endothelial sprouts and filopodia are rare (NogueraTroise et al. 2006; J.-L. Li and A.L. Harris, pers. comm.). Consistent with a putative role of Notch in tubulogenesis, conspicuously poorly branched and large /described as "dilated"| vessels have been reported in mice overexpressing the Notch4 ICD in ECs (Uyttendaele et al. 2001; Carlson et al. 2005). Although this question still requires direct experimental confirmation, we speculate that Notch-mediated suppression of endothelial sprouting 
might help to promote tubulogenesis in the growing vasculature and thereby integrate these two processes in the angiogenic growth program.

\section{Notch controls epithelial sprouting and branching}

The role of Delta-like ligand-mediated Notch signaling and its effect on sprouting processes appear remarkably conserved among vertebrate and invertebrate organisms (Fig. 6). The most striking example is the patterning of the Drosophila respiratory system, the trachea, which is a highly branched network formed by a monolayer of epithelial cells that allows the passive diffusion of oxygen from the outside (Zelzer and Shilo 2000; Ghabrial et al. 2003; Ribeiro et al. 2004). During the branching morphogenesis of the tracheal system in fly larvae, epithelial cells migrate and sprout in a highly stereotypic pattern and can acquire one of three different fates within the network. General tube cells assemble into main tubes and secondary branches. Specialized terminal cells at the ends of these tubes form long cellular, lumen-containing extensions into the target tissues. Due to the segmented organization of insects, a third type of cell, termed a fusion cell, is required to interconnect the tracheal tubes of adjacent body segments (Zelzer and Shilo 2000; Ghabrial et al. 2003). Tracheal cells express the receptor tyrosine kinase Breathless (Btl), and it has been shown that migration, sprouting, and fate determination processes of these cells are critically controlled by the expression of the corresponding ligand, an FGF-like molecule termed Branchless, in the surrounding tissues. Surprisingly, Breathless activity is essential only in the single leading cell within each tracheal sprout whereas the other, trailing epithelial cells can follow this tip cell and form the stalk even when they lack Btl /Ghabrial and
Krasnow 2006). Similar to the connection between VEGF-A signaling and D114 in the vertebrate vasculature, Branchless induces the expression of the Notch ligand Delta in the tip of growing tracheal sprouts. In Notch mutant Drosophila embryos, many cells try to lead the tracheal branches and compete for the lead position (Ghabrial and Krasnow 2006). Conversely, expression of constitutively active Notch prevents outgrowth, presumably due to the lack of leading tip cells (Ghabrial and Krasnow 2006). The Dll-Notch signal also prevents the stalk epithelium from becoming terminal or fusion cells (Fig. 6; Zelzer and Shilo 2000). The exact fate of tip cells is determined by other signals such as expression of the zinc finger transcription factor Escargot in presumptive fusion cells. In contrast, the long hollow terminal cells can be identified based on the expression of the FGF antagonist sprouty and the transcriptional regulators pointed (pnt) and serum response factor (Blistered/ Pruned) (Zelzer and Shilo 2000).

The role of Notch as a tip cell repressor is repeated during the development of the Malpighian tubules, the excretory system of Drosophila and other insects (Fig. 6). Signaling by the Wnt family molecule wingless induces the expression of Delta in a single tip cell within a cluster of primordial cells. Lateral inhibition through Notch activation restricts the expression of the transcriptional regulators krüppel and achaete to the tip cell. Accordingly, tip cells are absent after ectopic expression of the Notch intracellular domain throughout the developing Malpighian tubules (Hoch et al. 1994; Wan et al. 2000).

\section{Dll4-Notch signaling in tumor angiogenesis}

The neovascularization of tumors through the angiogenic ingrowth of blood vessels from the surrounding

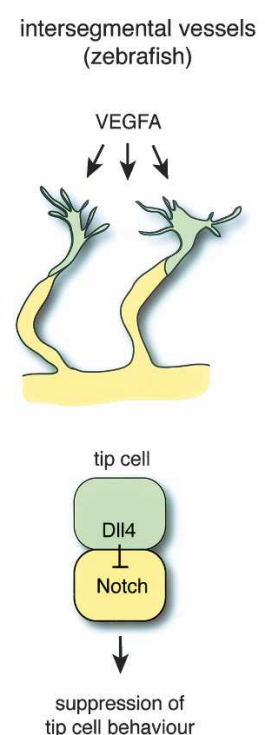

tip cell behaviour

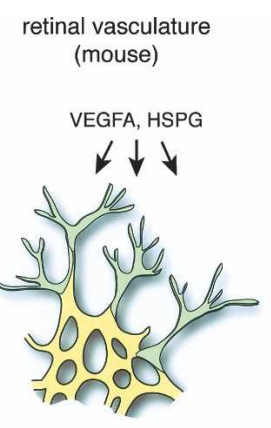

tracheal system

(Drosophila)
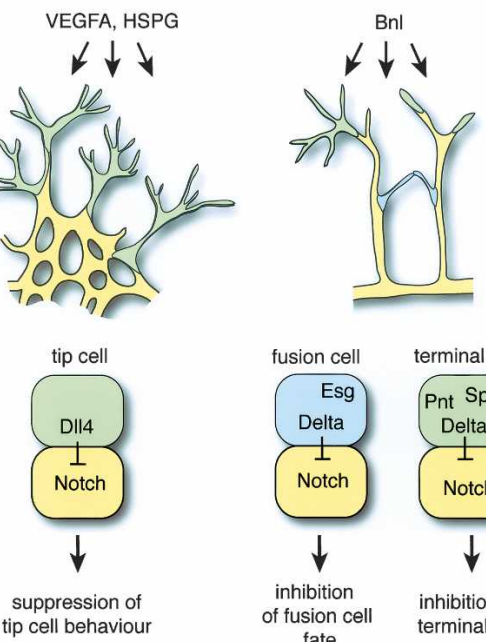

Malphigian tubules (Drosophila)
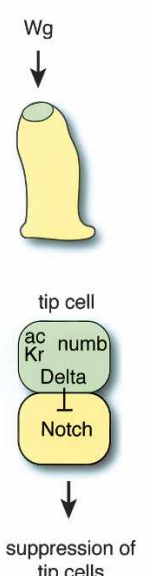

Figure 6. Regulation of endothelial and epithelial sprouting by Notch. Directional EC sprouting is controlled by gradients of heparan sulfate proteoglycan (HSGP)-bound VEGF-A. Endothelial Dll4 expression is up-regulated in response to VEGF. Activation of Notch in adjacent ECs down-regulates VEGFR-2 expression and suppresses tip cell behavior in these cells. In the fly tracheal system, sprouting morphogenesis is regulated by the growth factor Branchless and its receptor, the tyrosine kinase Breathless. Branchless induces Delta expression in the tip of tracheal sprouts. Notch activation prevents adjacent epithelial cells from acquiring a terminal cell or fusion cell fate. Presumptive fusion cells are positive for the zinc finger transcription factor Escargot (Esg), whereas the long hollow terminal cells express the FGF antagonist sprouty and the transcriptional regulators pointed (pnt) and serum response factor (Blistered/Pruned). Delta expression, induced by wingless $(\mathrm{Wg})$, is confined to single tip cells during sprouting of Malpighian tubules. Notch activation suppresses the expression of the transcriptional regulators and tip cell markers krüppel $(\mathrm{Kr})$ and achaete (ac). 
tissue is one of the hallmarks of cancer that promotes tumor growth and metastasis (Hanahan and Weinberg 2000). Suggesting that the important role of Dll4 and Notch signaling is not restricted to only developmental angiogenesis, Dll4 is prominently expressed in tumor blood vessels in a VEGF-dependent fashion (Patel et al. 2005, 2006; Hainaud et al. 2006; Noguera-Troise et al. 2006). Indeed, blockade of Dll4-Notch signaling with the Dll4/Fc antagonist, anti-Dll4 antibodies, or $\gamma$-secretase inhibitor promotes endothelial sprouting and thereby increases vascular density in xenograft tumor models in mice (Noguera-Troise et al. 2006; Ridgway et al. 2006; Scehnet et al. 2007). Surprisingly, inhibition of Dll4 with these strategies yields significantly smaller tumors compared with control animals. The analysis of blood vessel functionality provides an explanation for this seemingly paradoxical effect. Although Dll4 targeting strongly enhances angiogenic growth, the resulting blood vessel network is poorly perfused, and hypoxia in the surrounding tumor tissue is increased (Noguera-Troise et al. 2006; J.-L. Li and A.L. Harris, pers. comm.). These findings demonstrate that the stimulation of nonproductive angiogenesis is a feasible strategy in the fight against cancer, which might in the future complement anti-angiogenic therapeutic approaches.

Two other findings highlight the potential benefit of therapies aiming at the Notch pathway. Firstly, despite the expression of Dll4 in normal tissues, the viability of the treated animals is not compromised by the antagonistic effect of Dll4/Fc fusion protein or anti-Dll4 antibodies (Noguera-Troise et al. 2006; Ridgway et al. 2006). Whereas disruption of Notch signaling with the $\gamma$-secretase inhibitor dibenzazepine (DBZ) disturbs homeostasis in the mouse small intestine, administration of anti-Dll4 antibody twice weekly for 6 wk has no such adverse effects (Ridgway et al. 2006). Even more importantly, Dll4 inhibition reduces the growth of solid tumors that are resistant to VEGF blockade and therefore not susceptible to treatment with avastin or other VEGF antagonists (Noguera-Troise et al. 2006; J.-L. Li and A.L. Harris, pers. comm.). Future work will have to address whether anti-Dll4 therapy is equally successful for other mouse tumor models and in human patients. Given the functional roles of Dll4 in hematopoiesis and T-cell differentiation (Amsen et al. 2004; Radtke et al. 2004), the safety of long-term treatment needs to be investigated in greater detail. It is also unclear whether tumors can acquire resistance against Dll4 disruption; for example, by up-regulating other Notch ligands. In this context, it is noteworthy that Notch responses may be ligand dependent. The overexpression of Jagged 1 by carcinoma cells promotes angiogenesis and tumor growth (Zeng et al. 2005).

\section{Role of Notch in vascular disease}

The importance of Notch signaling in development and disease is further highlighted by the fact that its impairment is responsible for two congenital diseases that affect the vasculature, the Alagille syndrome (AGS) and the cerebral autosomal dominant arteriopathy with subcortical infarcts and leukoencephalopathy (CADASIL).

AGS is a congenital disorder caused by mutations in the human gene for Jagged1 (JAG1). Symptoms include abnormalities affecting the liver, heart, eye, and skeleton (Oda et al. 1997). The most frequent cardiovascular anomalies in AGS patients are peripheral pulmonic stenosis, coarctation of the aorta, atrial and ventricular septal defects, and tetralogy of Fallot (Krantz et al. 1999; McElhinney et al. 2002). AGS is caused by JAG1 haploinsufficiency, but the exact role of Jagged 1 in the affected tissues is unclear (Spinner et al. 2001). While heterozygous Jagged1 knockout mice do not recapitulate AGS, the additional introduction of a single Notch2 hypomorphic allele leads to Alagille-like developmental abnormalities (Xue et al. 1999; McCright et al. 2002).

CADASIL is a hereditary vascular degenerative disorder caused by mutations in the human NOTCH3 gene. This syndrome is characterized by arteriopathy that affects mainly the small cerebral arteries and leads to stroke and dementia in humans (Joutel et al. 1997, 2004; Kalaria et al. 2004). Consistent with the expression pattern of Notch3 within blood vessels, degeneration and loss of vSMCs are main features of CADASIL and are accompanied by the progressive accumulation of extracellular matrix and the appearance of perivascular GOM deposits (i.e., granular osmiophilic material visible by electron microscopy). These processes cause the thickening of the vessel wall and narrow the lumen of the affected arteries (Chabriat et al. 1995). The genetic defects in CADASIL are typically missense mutations, most of which translate into amino acid exchanges within the first five EGF-like repeats of the NOTCH3 ectodomain (Joutel et al. 1997). It is thought that CADASIL mutations alter the intracellular trafficking and maturation but not the signaling by NOTCH3 (Haritunians et al. 2002; Karlstrom et al. 2002). Smooth muscle-specific overexpression of NOTCH3 containing a CADASIL mutation in transgenic mice reproduces many of the characteristic disease symptoms (Ruchoux et al. 2003).

The etiology of AGS and CADASIL remain insufficiently understood, so that the recent advancements in understanding the role of Notch in the vasculature may allow new insight into the pathogenesis of these important diseases.

\section{Perspectives}

The many examples in this review show that the Notch pathway plays a particularly important role during vascular morphogenesis. Its numerous functions include some of the most fundamental processes, such as the specification of AV identity or the selection of ECs for angiogenic sprouting. By suppressing the tip cell phenotype, Notch signaling may simultaneously promote tubulogenesis, but this question requires further investigation. Similarly, the versatile functions of Notch in the vasculature can be only partially explained by its links to the VEGF pathway. Future work will need to address the 
role of other signaling cascades and relevant interaction partners.

The analysis of Notch signaling in the vasculature is complicated by the essential roles of Notch receptors, their DSL ligands, downstream signaling partners, and molecular modulators in early embryogenesis. Due to the lethality of the global knockout mice, we know relatively little about Notch function in the postnatal vasculature and in pathological processes. Much of what we know is based on studies with heterozygous mutant mice displaying haploinsufficiency or the administration of inhibitors. Some of the latter, such as $\gamma$-secretase inhibitors, also affect other signaling pathways and may thereby distort experimental results. Despite these limitations, there is already good evidence that Notch signaling and Dll4 critically regulate tumor angiogenesis. Dll4 looks like a promising therapeutic target, especially in the case of tumors that are resistant against antiVEGF therapy. The combination of anti-Dll4 treatment with other therapies might improve the outlook for some of the cancers that are currently difficult to treat.

The haploinsufficiency for Dll1 in adult arteriogenesis and Jagged1 in AGS indicate that the activity of these DSL ligands is also rate-limiting in certain processes, but their exact biological roles remain unclear. More detailed functional characterization of these and other Notch pathway molecules should improve our understanding of the blood vessel growth program and may, at the same time, uncover novel therapeutic opportunities.

\section{Acknowledgments}

We thank Cancer Research UK for their support and R. Benedito for the immunofluorescence image in Figure 5.

\section{References}

Adams, R.H. and Alitalo, K. 2007. Molecular regulation of angiogenesis and lymphangiogenesis. Nat. Rev. Mol. Cell Biol. 8: 464-478.

Amsen, D., Blander, J.M., Lee, G.R., Tanigaki, K., Honjo, T., and Flavell, R.A. 2004. Instruction of distinct CD4 T helper cell fates by different Notch ligands on antigen-presenting cells. Cell 117: 515-526.

Beckers, J., Clark, A., Wunsch, K., Hrabe De Angelis, M., and Gossler, A. 1999. Expression of the mouse Deltal gene during organogenesis and fetal development. Mech. Dev. 84: $165-168$.

Bray, S.J. 2006. Notch signalling: A simple pathway becomes complex. Nat. Rev. Mol. Cell Biol. 7: 678-689.

Carlson, T.R., Yan, Y., Wu, X., Lam, M.T., Tang, G.L., Beverly, L.J., Messina, L.M., Capobianco, A.J., Werb, Z., and Wang, R. 2005. Endothelial expression of constitutively active Notch4 elicits reversible arteriovenous malformations in adult mice. Proc. Natl. Acad. Sci. 102: 9884-9889.

Carmeliet, P. 2003. Angiogenesis in health and disease. Nat. Med. 9: 653-660.

Chabriat, H., Vahedi, K., Iba-Zizen, M.T., Joutel, A., Nibbio, A., Nagy, T.G., Krebs, M.O., Julien, J., Dubois, B., Ducrocq, X., et al. 1995. Clinical spectrum of CADASIL: A study of 7 families. Cerebral autosomal dominant arteriopathy with subcortical infarcts and leukoencephalopathy. Lancet 346:
934-939.

Chitnis, A. 2006. Why is Delta endocytosis required for effective activation of Notch? Dev. Dyn. 235: 886-894.

Claxton, S. and Fruttiger, M. 2004. Periodic Delta-like 4 expression in developing retinal arteries. Brain Res. Gene Expr. Patterns 5: 123-127.

Devgan, V., Mammucari, C., Millar, S.E., Brisken, C., and Dotto, G.P. 2005. p21WAF1/Cip1 is a negative transcriptional regulator of Wnt4 expression downstream of Notch1 activation. Genes \& Dev. 19: 1485-1495.

Diez, H., Fischer, A., Winkler, A., Hu, C.J., Hatzopoulos, A.K., Breier, G., and Gessler, M. 2007. Hypoxia-mediated activation of Dll4-Notch-Hey2 signaling in endothelial progenitor cells and adoption of arterial cell fate. Exp. Cell Res. 313: $1-9$.

Domenga, V., Fardoux, P., Lacombe, P., Monet, M., Maciazek, J., Krebs, L.T., Klonjkowski, B., Berrou, E., Mericskay, M., Li, Z., et al. 2004. Notch3 is required for arterial identity and maturation of vascular smooth muscle cells. Genes \& Dev. 18: $2730-2735$.

Dorrell, M.I. and Friedlander, M. 2006. Mechanisms of endothelial cell guidance and vascular patterning in the developing mouse retina. Prog. Retin. Eye Res. 25: 277-295.

Dorrell, M.I., Aguilar, E., and Friedlander, M. 2002. Retinal vascular development is mediated by endothelial filopodia, a preexisting astrocytic template and specific R-cadherin adhesion. Invest. Ophthalmol. Vis. Sci. 43: 3500-3510.

Duarte, A., Hirashima, M., Benedito, R., Trindade, A., Diniz, P., Bekman, E., Costa, L., Henrique, D., and Rossant, J. 2004. Dosage-sensitive requirement for mouse Dll4 in artery development. Genes \& Dev. 18: 2474-2478.

Duncan, A.W., Rattis, F.M., DiMascio, L.N., Congdon, K.L., Pazianos, G., Zhao, C., Yoon, K., Cook, J.M., Willert, K., Gaiano, N., et al. 2005. Integration of Notch and Wnt signaling in hematopoietic stem cell maintenance. Nat. Immunol. 6: 314-322.

Ehebauer, M., Hayward, P., and Martinez-Arias, A. 2006. Notch signaling pathway. Sci. STKE 2006: cm7. doi: 10.1126/ stke. $3642006 \mathrm{~cm} 7$.

Erber, R., Eichelsbacher, U., Powajbo, V., Korn, T., Djonov, V., Lin, J., Hammes, H.P., Grobholz, R., Ullrich, A., and Vajkoczy, P. 2006. EphB4 controls blood vascular morphogenesis during postnatal angiogenesis. EMBO J. 25: 628-641.

Fischer, A. and Gessler, M. 2003. Hey genes in cardiovascular development. Trends Cardiovasc. Med. 13: 221-226.

Fischer, A., Schumacher, N., Maier, M., Sendtner, M., and Gessler, M. 2004. The Notch target genes Hey1 and Hey2 are required for embryonic vascular development. Genes \& Dev. 18: 901-911.

Flamme, I., Frolich, T., and Risau, W. 1997. Molecular mechanisms of vasculogenesis and embryonic angiogenesis. J. Cell. Physiol. 173: 206-210.

Fruttiger, M. 2007. Development of the retinal vasculature. Angiogenesis 10: 77-88.

Gale, N.W., Dominguez, M.G., Noguera, I., Pan, L., Hughes, V., Valenzuela, D.M., Murphy, A.J., Adams, N.C., Lin, H.C., Holash, J., et al. 2004. Haploinsufficiency of Delta-like 4 ligand results in embryonic lethality due to major defects in arterial and vascular development. Proc. Natl. Acad. Sci. 101: 15949-15954.

Gariano, R.F. 2003. Cellular mechanisms in retinal vascular development. Prog. Retin. Eye Res. 22: 295-306.

Gerhardt, H., Golding, M., Fruttiger, M., Ruhrberg, C., Lundkvist, A., Abramsson, A., Jeltsch, M., Mitchell, C., Alitalo, K., Shima, D., et al. 2003. VEGF guides angiogenic sprouting utilizing endothelial tip cell filopodia. J. Cell Biol. 161: 
$1163-1177$

Ghabrial, A.S. and Krasnow, M.A. 2006. Social interactions among epithelial cells during tracheal branching morphogenesis. Nature 441: 746-749.

Ghabrial, A., Luschnig, S., Metzstein, M.M., and Krasnow, M.A. 2003. Branching morphogenesis of the Drosophila tracheal system. Annu. Rev. Cell Dev. Biol. 19: 623-647.

Giudicelli, F. and Lewis, J. 2004. The vertebrate segmentation clock. Curr. Opin. Genet. Dev. 14: 407-414.

Hainaud, P., Contreres, J.O., Villemain, A., Liu, L.X., Plouet, J., Tobelem, G., and Dupuy, E. 2006. The role of the vascular endothelial growth factor-Delta-like 4 ligand/Notch4-ephrin B2 cascade in tumor vessel remodeling and endothelial cell functions. Cancer Res. 66: 8501-8510.

Haines, N. and Irvine, K.D. 2003. Glycosylation regulates Notch signalling. Nat. Rev. Mol. Cell Biol. 4: 786-797.

Hanahan, D. and Weinberg, R.A. 2000. The hallmarks of cancer. Cell 100: 57-70.

Haritunians, T., Boulter, J., Hicks, C., Buhrman, J., DiSibio, G., Shawber, C., Weinmaster, G., Nofziger, D., and Schanen, C. 2002. CADASIL Notch 3 mutant proteins localize to the cell surface and bind ligand. Circ. Res. 90: 506-508.

Heil, M., Eitenmuller, I., Schmitz-Rixen, T., and Schaper, W. 2006. Arteriogenesis versus angiogenesis: Similarities and differences. J. Cell. Mol. Med. 10: 45-55.

Hellström, M., Phng, L.K., Hofmann, J.J., Wallgard, E., Coultas, L., Lindblom, P., Alva, J., Nilsson, A.K., Karlsson, L., Gaiano, N., et al. 2007. Dll4 signalling through Notch1 regulates formation of tip cells during angiogenesis. Nature 445: 776 780.

Hoch, M., Broadie, K., Jackle, H., and Skaer, H. 1994. Sequential fates in a single cell are established by the neurogenic cascade in the Malpighian tubules of Drosophila. Development 120: $3439-3450$

Hofmann, J.J. and Iruela-Arispe, L. 2007. Notch expression patterns in the retina: An eye on receptor-ligand distribution during angiogenesis. Brain Res. Gene Expr. Patterns 7: 461470.

Holley, S.A. and Takeda, H. 2002. Catching a wave: The oscillator and wavefront that create the zebrafish somite. Semin. Cell Dev. Biol. 13: 481-488.

Hrabe de Angelis, M., McIntyre II, J., and Gossler, A. 1997. Maintenance of somite borders in mice requires the Delta homologue DII1. Nature 386: 717-721.

Hurlbut, G.D., Kankel, M.W., Lake, R.J., and Artavanis-Tsakonas, S. 2007. Crossing paths with Notch in the hyper-network. Curr. Opin. Cell Biol. 19: 166-175.

Irvine, K.D. 1999. Fringe, Notch, and making developmental boundaries. Curr. Opin. Genet. Dev. 9: 434-441.

Iso, T., Kedes, L., and Hamamori, Y. 2003. HES and HERP families: Multiple effectors of the Notch signaling pathway. $J$. Cell. Physiol. 194: 237-255.

Isogai, S., Lawson, N.D., Torrealday, S., Horiguchi, M., and Weinstein, B.M. 2003. Angiogenic network formation in the developing vertebrate trunk. Development 130: 5281-5290.

Jain, R.K. 2003. Molecular regulation of vessel maturation. Nat. Med. 9: 685-693.

Joutel, A., Vahedi, K., Corpechot, C., Troesch, A., Chabriat, H., Vayssiere, C., Cruaud, C., Maciazek, J., Weissenbach, J., Bousser, M.G., et al. 1997. Strong clustering and stereotyped nature of Notch3 mutations in CADASIL patients. Lancet 350: $1511-1515$.

Joutel, A., Monet, M., Domenga, V., Riant, F., and TournierLasserve, E. 2004. Pathogenic mutations associated with cerebral autosomal dominant arteriopathy with subcortical infarcts and leukoencephalopathy differently affect Jaggedl binding and Notch 3 activity via the RBP/JK signaling pathway. Am. J. Hum. Genet. 74: 338-347.

Kalaria, R.N., Viitanen, M., Kalimo, H., Dichgans, M., and Tabira, T. 2004. The pathogenesis of CADASIL: An update. J. Neurol. Sci. 226: 35-39.

Karlstrom, H., Beatus, P., Dannaeus, K., Chapman, G., Lendahl, U., and Lundkvist, J. 2002. A CADASIL-mutated Notch 3 receptor exhibits impaired intracellular trafficking and maturation but normal ligand-induced signaling. Proc. Nat1. Acad. Sci. 99: 17119-17124.

Koo, B.K., Lim, H.S., Song, R., Yoon, M.J., Yoon, K.J., Moon, J.S., Kim, Y.W., Kwon, M.C., Yoo, K.W., Kong, M.P., et al. 2005. Mind bomb 1 is essential for generating functional Notch ligands to activate Notch. Development 132: 3459-3470.

Krantz, I.D., Smith, R., Colliton, R.P., Tinkel, H., Zackai, E.H., Piccoli, D.A., Goldmuntz, E., and Spinner, N.B. 1999. Jagged 1 mutations in patients ascertained with isolated congenital heart defects. Am. J. Med. Genet. 84: 56-60.

Krebs, L.T., Xue, Y., Norton, C.R., Shutter, J.R., Maguire, M., Sundberg, J.P., Gallahan, D., Closson, V., Kitajewski, J., Callahan, R., et al. 2000. Notch signaling is essential for vascular morphogenesis in mice. Genes \& Dev. 14: 1343-1352.

Krebs, L.T., Shutter, J.R., Tanigaki, K., Honjo, T., Stark, K.L., and Gridley, T. 2004. Haploinsufficient lethality and formation of arteriovenous malformations in Notch pathway mutants. Genes \& Dev. 18: 2469-2473.

Lai, E.C. 2002a. Keeping a good pathway down: Transcriptional repression of Notch pathway target genes by CSL proteins. EMBO Rep. 3: 840-845.

Lai, E.C. 2002b. Protein degradation: Four E3s for the Notch pathway. Curr. Biol. 12: R74-R78.

Lai, E.C. 2004. Notch signaling: Control of cell communication and cell fate. Development 131: 965-973.

Lawson, N.D., Scheer, N., Pham, V.N., Kim, C.H., Chitnis, A.B., Campos-Ortega, J.A., and Weinstein, B.M. 2001. Notch signaling is required for arterial-venous differentiation during embryonic vascular development. Development 128: 3675 3683.

Lawson, N.D., Vogel, A.M., and Weinstein, B.M. 2002. sonic hedgehog and vascular endothelial growth factor act upstream of the Notch pathway during arterial endothelial differentiation. Dev. Cell 3: 127-136.

Le Borgne, R. and Schweisguth, F. 2003. Notch signaling: Endocytosis makes Delta signal better. Curr. Biol. 13: R273R275. doi: 10.1016/S0960-9822/03/00199-4.

Le Borgne, R., Bardin, A., and Schweisguth, F. 2005. The roles of receptor and ligand endocytosis in regulating Notch signaling. Development 132: 1751-1762.

Leong, K.G., Hu, X., Li, L., Noseda, M., Larrivee, B., Hull, C., Hood, L., Wong, F., and Karsan, A. 2002. Activated Notch4 inhibits angiogenesis: Role of $\beta$ 1-integrin activation. Mol. Cell. Biol. 22: 2830-2841.

Leslie, J.D., Ariza-McNaughton, L., Bermange, A.L., McAdow, R., Johnson, S.L., and Lewis, J. 2007. Endothelial signalling by the Notch ligand Delta-like 4 restricts angiogenesis. Development 134: 839-844.

Limbourg, A., Ploom, M., Elligsen, D., Sorensen, I., Ziegelhoeffer, T., Gossler, A., Drexler, H., and Limbourg, F.P. 2007. Notch ligand Delta-like 1 is essential for postnatal arteriogenesis. Circ. Res. 100: 363-371.

Liu, Z.J., Shirakawa, T., Li, Y., Soma, A., Oka, M., Dotto, G.P., Fairman, R.M., Velazquez, O.C., and Herlyn, M. 2003. Regulation of Notch1 and Dll4 by vascular endothelial growth factor in arterial endothelial cells: Implications for modulating arteriogenesis and angiogenesis. Mol. Cell. Biol. 23: 1425. 
Lobov, I.B., Renard, R.A., Papadopoulos, N., Gale, N.W., Thurston, G., Yancopoulos, G.D., and Wiegand, S.J. 2007. Deltalike ligand 4 (D1l4) is induced by VEGF as a negative regulator of angiogenic sprouting. Proc. Natl. Acad. Sci. 104: 3219-3224.

MacKenzie, F., Duriez, P., Larrivee, B., Chang, L., Pollet, I., Wong, F., Yip, C., and Karsan, A. 2004. Notch4-induced inhibition of endothelial sprouting requires the ankyrin repeats and involves signaling through RBP-Jк. Blood 104: $1760-1768$

Mailhos, C., Modlich, U., Lewis, J., Harris, A., Bicknell, R., and Ish-Horowicz, D. 2001. Delta4, an endothelial specific Notch ligand expressed at sites of physiological and tumor angiogenesis. Differentiation 69: 135-144.

Martinez Arias, A., Zecchini, V., and Brennan, K. 2002. CSLindependent Notch signalling: A checkpoint in cell fate decisions during development? Curr. Opin. Genet. Dev. 12: 524-533.

McCright, B., Lozier, J., and Gridley, T. 2002. A mouse model of Alagille syndrome: Notch2 as a genetic modifier of Jag1 haploinsufficiency. Development 129: 1075-1082.

McElhinney, D.B., Krantz, I.D., Bason, L., Piccoli, D.A., Emerick, K.M., Spinner, N.B., and Goldmuntz, E. 2002. Analysis of cardiovascular phenotype and genotype-phenotype correlation in individuals with a JAG1 mutation and/or Alagille syndrome. Circulation 106: 2567-2574.

Nakatsu, M.N., Sainson, R.C., Perez-del-Pulgar, S., Aoto, J.N., Aitkenhead, M., Taylor, K.L., Carpenter, P.M., and Hughes, C.C. 2003. VEGF(121) and VEGF(165) regulate blood vessel diameter through vascular endothelial growth factor receptor 2 in an in vitro angiogenesis model. Lab. Invest. 83: $1873-1885$.

Nichols, J.T., Miyamoto, A., Olsen, S.L., D'Souza, B., Yao, C., and Weinmaster, G. 2007a. DSL ligand endocytosis physically dissociates Notch1 heterodimers before activating proteolysis can occur. J. Cell Biol. 176: 445-458.

Nichols, J.T., Miyamoto, A., and Weinmaster, G. 2007b. Notch signaling-Constantly on the move. Traffic 8: 959-969.

Noguera-Troise, I., Daly, C., Papadopoulos, N.J., Coetzee, S., Boland, P., Gale, N.W., Lin, H.C., Yancopoulos, G.D., and Thurston, G. 2006. Blockade of Dll4 inhibits tumour growth by promoting non-productive angiogenesis. Nature 444: 1032-1037.

Noseda, M., Chang, L., McLean, G., Grim, J.E., Clurman, B.E., Smith, L.L., and Karsan, A. 2004. Notch activation induces endothelial cell cycle arrest and participates in contact inhibition: Role of p21Cip1 repression. Mol. Cell. Biol. 24: 8813-8822.

Oda, T., Elkahloun, A.G., Pike, B.L., Okajima, K., Krantz, I.D., Genin, A., Piccoli, D.A., Meltzer, P.S., Spinner, N.B., Collins, F.S., et al. 1997. Mutations in the human Jagged1 gene are responsible for Alagille syndrome. Nat. Genet. 16: 235242.

Overstreet, E., Fitch, E., and Fischer, J.A. 2004. Fat facets and Liquid facets promote Delta endocytosis and Delta signaling in the signaling cells. Development 131: 5355-5366.

Patel, N.S., Li, J.L., Generali, D., Poulsom, R., Cranston, D.W., and Harris, A.L. 2005. Up-regulation of Delta-like 4 ligand in human tumor vasculature and the role of basal expression in endothelial cell function. Cancer Res. 65: 8690-8697.

Patel, N.S., Dobbie, M.S., Rochester, M., Steers, G., Poulsom, R., Le Monnier, K., Cranston, D.W., Li, J.L., and Harris, A.L. 2006. Up-regulation of endothelial Delta-like 4 expression correlates with vessel maturation in bladder cancer. Clin. Cancer Res. 12: 4836-4844.

Pitsouli, C. and Delidakis, C. 2005. The interplay between DSL proteins and ubiquitin ligases in Notch signaling. Development 132: 4041-4050.

Pourquie, O. 2003. The segmentation clock: Converting embryonic time into spatial pattern. Science 301: 328-330.

Radtke, F., Wilson, A., Mancini, S.J., and MacDonald, H.R. 2004. Notch regulation of lymphocyte development and function. Nat. Immunol. 5: 247-253.

Ribeiro, C., Neumann, M., and Affolter, M. 2004. Genetic control of cell intercalation during tracheal morphogenesis in Drosophila. Curr. Biol. 14: 2197-2207.

Ridgway, J., Zhang, G., Wu, Y., Stawicki, S., Liang, W.C., Chanthery, Y., Kowalski, J., Watts, R.J., Callahan, C., Kasman, I., et al. 2006. Inhibition of Dll4 signalling inhibits tumour growth by deregulating angiogenesis. Nature 444: 1083-1087.

Risau, W. and Flamme, I. 1995. Vasculogenesis. Annu. Rev. Cell Dev. Biol. 11: 73-91.

Ruchoux, M.M., Domenga, V., Brulin, P., Maciazek, J., Limol, S., Tournier-Lasserve, E., and Joutel, A. 2003. Transgenic mice expressing mutant Notch3 develop vascular alterations characteristic of cerebral autosomal dominant arteriopathy with subcortical infarcts and leukoencephalopathy. Am. J. Pathol. 162: 329-342.

Ruhrberg, C., Gerhardt, H., Golding, M., Watson, R., Ioannidou, S., Fujisawa, H., Betsholtz, C., and Shima, D.T. 2002. Spatially restricted patterning cues provided by heparin-binding VEGF-A control blood vessel branching morphogenesis. Genes \& Dev. 16: 2684-2698.

Sainson, R.C., Aoto, J., Nakatsu, M.N., Holderfield, M., Conn, E., Koller, E., and Hughes, C.C. 2005. Cell-autonomous Notch signaling regulates endothelial cell branching and proliferation during vascular tubulogenesis. FASEB I. 19: 1027-1029.

Sakata, T., Sakaguchi, H., Tsuda, L., Higashitani, A., Aigaki, T., Matsuno, K., and Hayashi, S. 2004. Drosophila Nedd4 regulates endocytosis of Notch and suppresses its ligand-independent activation. Curr. Biol. 14: 2228-2236.

Sarmento, L.M., Huang, H., Limon, A., Gordon, W., Fernandes, J., Tavares, M.J., Miele, L., Cardoso, A.A., Classon, M., and Carlesso, N. 2005. Notch1 modulates timing of G1-S progression by inducing SKP2 transcription and p27 Kip1 degradation. J. Exp. Med. 202: 157-168.

Scehnet, J.S., Jiang, W., Kumar, S.R., Krasnoperov, V., Trindade, A., Benedito, R., Djokovic, D., Borges, C., Ley, E.J., Duarte, A., et al. 2007. Inhibition of Dll4-mediated signaling induces proliferation of immature vessels and results in poor tissue perfusion. Blood 109: 4753-4760.

Schweisguth, F. 2004. Regulation of Notch signaling activity. Curr. Biol. 14: R129-R138. doi: 10.1016/j.cub.2004.01.023.

Selkoe, D. and Kopan, R. 2003. Notch and Presenilin: Regulated intramembrane proteolysis links development and degeneration. Annu. Rev. Neurosci. 26: 565-597.

Shawber, C.J., Das, I., Francisco, E., and Kitajewski, J. 2003. Notch signaling in primary endothelial cells. Ann. N. Y. Acad. Sci. 995: 162-170.

Shi, S. and Stanley, P. 2003. Protein O-fucosyltransferase 1 is an essential component of Notch signaling pathways. Proc. Natl. Acad. Sci. 100: 5234-5239.

Shutter, J.R., Scully, S., Fan, W., Richards, W.G., Kitajewski, J., Deblandre, G.A., Kintner, C.R., and Stark, K.L. 2000. Dll4, a novel Notch ligand expressed in arterial endothelium. Genes \& Dev. 14: 1313-1318.

Siekmann, A.F. and Lawson, N.D. 2007. Notch signalling limits angiogenic cell behaviour in developing zebrafish arteries. Nature 445: 781-784.

Spinner, N.B., Colliton, R.P., Crosnier, C., Krantz, I.D., Had- 
chouel, M., and Meunier-Rotival, M. 2001. Jagged1 mutations in alagille syndrome. Hum. Mutat. 17: 18-33.

Stone, J., Itin, A., Alon, T., Pe'er, J., Gnessin, H., Chan-Ling, T., and Keshet, E. 1995. Development of retinal vasculature is mediated by hypoxia-induced vascular endothelial growth factor (VEGF) expression by neuroglia. I. Neurosci. 15: 47384747.

Struhl, G., Fitzgerald, K., and Greenwald, I. 1993. Intrinsic activity of the Lin-12 and Notch intracellular domains in vivo. Cell 74: 331-345.

Suchting, S., Freitas, C., le Noble, F., Benedito, R., Breant, C., Duarte, A., and Eichmann, A. 2007. The Notch ligand Deltalike 4 negatively regulates endothelial tip cell formation and vessel branching. Proc. Natl. Acad. Sci. 104: 3225-3230.

Takeshita, K., Satoh, M., Ii, M., Silver, M., Limbourg, F.P., Mukai, Y., Rikitake, Y., Radtke, F., Gridley, T., Losordo, D.W., et al. 2007. Critical role of endothelial Notch1 signaling in postnatal angiogenesis. Circ. Res. 100: 70-78.

Taylor, K.L., Henderson, A.M., and Hughes, C.C. 2002. Notch activation during endothelial cell network formation in vitro targets the basic HLH transcription factor HESR-1 and downregulates VEGFR-2/KDR expression. Microvasc. Res. 64: $372-383$.

Tian, X., Hansen, D., Schedl, T., and Skeath, J.B. 2004. Epsin potentiates Notch pathway activity in Drosophila and C. elegans. Development 131: 5807-5815.

Torres-Vazquez, J., Gitler, A.D., Fraser, S.D., Berk, J.D., Van, N.P., Fishman, M.C., Childs, S., Epstein, J.A., and Weinstein, B.M. 2004. Semaphorin-plexin signaling guides patterning of the developing vasculature. Dev. Cell 7: 117-123.

Uyttendaele, H., Ho, J., Rossant, J., and Kitajewski, J. 2001. Vascular patterning defects associated with expression of activated Notch4 in embryonic endothelium. Proc. Nat1. Acad. Sci. 98: 5643-5648.

Vooijs, M., Ong, C.T., Hadland, B., Huppert, S., Liu, Z., Korving, J., van den Born, M., Stappenbeck, T., Wu, Y., Clevers, H., et al. 2007. Mapping the consequence of Notch1 proteolysis in vivo with NIP-CRE. Development 134: 535-544.

Wan, S., Cato, A.M., and Skaer, H. 2000. Multiple signalling pathways establish cell fate and cell number in Drosophila malpighian tubules. Dev. Biol. 217: 153-165.

Wang, W. and Struhl, G. 2004. Drosophila Epsin mediates a select endocytic pathway that DSL ligands must enter to activate Notch. Development 131: 5367-5380.

Wang, W. and Struhl, G. 2005. Distinct roles for Mind bomb, Neuralized and Epsin in mediating DSL endocytosis and signaling in Drosophila. Development 132: 2883-2894.

Weinmaster, G. 2000. Notch signal transduction: A real rip and more. Curr. Opin. Genet. Dev. 10: 363-369.

Wilkin, M.B. and Baron, M. 2005. Endocytic regulation of Notch activation and down-regulation. Mol. Membr. Biol. 22: 279289.

Wilkin, M.B., Carbery, A.M., Fostier, M., Aslam, H., Mazaleyrat, S.L., Higgs, J., Myat, A., Evans, D.A., Cornell, M., and Baron, M. 2004. Regulation of Notch endosomal sorting and signaling by Drosophila Nedd4 family proteins. Curr. Biol. 14: $2237-2244$.

Williams, C.K., Li, J.L., Murga, M., Harris, A.L., and Tosato, G. 2006. Up-regulation of the Notch ligand Delta-like 4 inhibits VEGF-induced endothelial cell function. Blood 107: 931939.

Xue, Y., Gao, X., Lindsell, C.E., Norton, C.R., Chang, B., Hicks, C., Gendron-Maguire, M., Rand, E.B., Weinmaster, G., and Gridley, T. 1999. Embryonic lethality and vascular defects in mice lacking the Notch ligand Jagged1. Hum. Mol. Genet. 8: 723-730.
You, L.R., Lin, F.J., Lee, C.T., DeMayo, F.J., Tsai, M.J., and Tsai, S.Y. 2005. Suppression of Notch signalling by the COUPTFII transcription factor regulates vein identity. Nature 435: 98-104.

Zelzer, E. and Shilo, B.Z. 2000. Cell fate choices in Drosophila tracheal morphogenesis. Bioessays 22: 219-226.

Zeng, Q., Li, S., Chepeha, D.B., Giordano, T.J., Li, J., Zhang, H., Polverini, P.J., Nor, J., Kitajewski, J., and Wang, C.Y. 2005. Crosstalk between tumor and endothelial cells promotes tumor angiogenesis by MAPK activation of Notch signaling. Cancer Cell 8: 13-23.

Zhong, T.P., Rosenberg, M., Mohideen, M.A., Weinstein, B., and Fishman, M.C. 2000. gridlock, an HLH gene required for assembly of the aorta in zebrafish. Science 287: 1820-1824.

Zhong, T.P., Childs, S., Leu, J.P., and Fishman, M.C. 2001. Gridlock signalling pathway fashions the first embryonic artery. Nature 414: 216-220. 


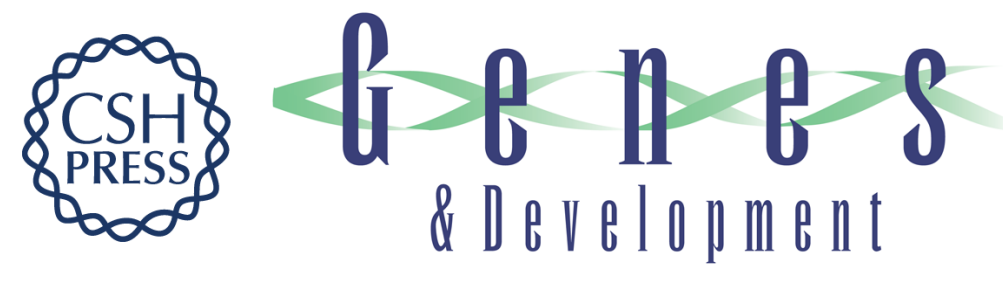

\section{Regulation of vascular morphogenesis by Notch signaling}

Cristina Roca and Ralf H. Adams

Genes Dev. 2007, 21:

Access the most recent version at doi:10.1101/gad.1589207

References This article cites 118 articles, 50 of which can be accessed free at: http://genesdev.cshlp.org/content/21/20/2511.full.html\#ref-list-1

License Freely available online through the Genes \& Development Open Access option.

Email Alerting Receive free email alerts when new articles cite this article - sign up in the box at the top Service right corner of the article or click here.

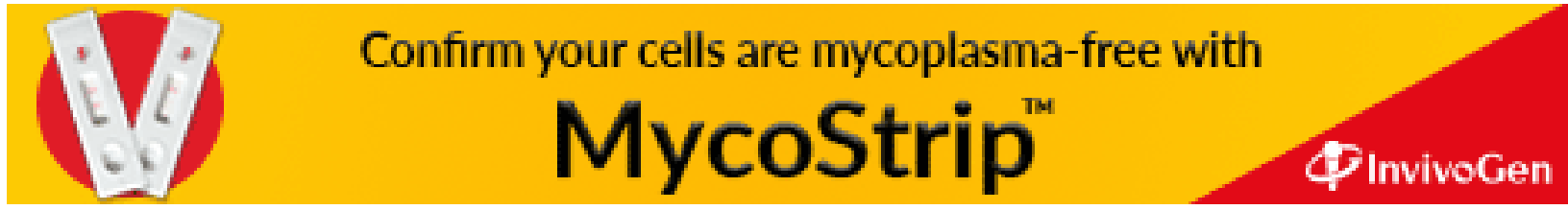

